Article

\title{
Daylight Performance of Classrooms in a Mediterranean School Heritage Building
}

\author{
Francesco Nocera ${ }^{1}\left(\mathbb{D}\right.$, Alessandro Lo Faro ${ }^{1, *} \mathbb{C}$, Vincenzo Costanzo ${ }^{2} \mathbb{D}$ and Chiara Raciti ${ }^{3}$ \\ 1 Department of Civil Engineering and Architecture, University of Catania, Via Santa Sofia, 64, 95123 Catania, \\ Italy; fnocera@unict.it \\ 2 Department of Electric, Electronic and Computer Engineering, University of Catania, Via Santa Sofia, 64, \\ 95123 Catania, Italy; costanzo.vincenzo@gmail.com \\ 3 Freelance Architect, 96100, Siracusa, Italy; chiararct@live.it \\ * Correspondence: alessandro.lofaro@darc.unict.it or alofaro@dau.unict.it; Tel.: +39-095-738-2527
}

Received: 11 September 2018; Accepted: 10 October 2018; Published: 16 October 2018

check for updates

\begin{abstract}
In school buildings, natural light has considerable physiological benefits, and increases energy efficiency while reducing the operational energy consumption of buildings. It is thus crucial to maximize the amount of daylight, as well as to improve its quality, in educational premises. In Italy and other European countries, many historic buildings are reused as school buildings, changing their original function. This process of adaptive reusing is one method for conserving heritage buildings, however sometimes this process sacrifices the quality of daylight and well being of pupils. It has therefore become apparent that it is difficult to reconcile the cultural value of historic buildings with comfort standards. This study aimed to investigate the natural lighting performance of a school located in an historic building, and proposes different technological solutions to improve the visual comfort in classrooms whilst also respecting the cultural value of built heritage. Daylight performance was carried out in a representative classroom in the 'Caserma Gaetano Abela', an historical building located in Siracusa (Italy). A daylight model built in Radiance was first validated against an illuminance measurement campaign, and was then used to run detailed dynamic simulations. Climate Based Daylight Modelling (CBDM) metrics were used to show the achievable improvements in visual comfort conditions by means of proposed retrofit interventions. These interventions may also be used in other areas of southern Europe with similar climatic and constructive/distributive characteristics of architectural heritage.
\end{abstract}

Keywords: daylight; historic building; school building; Groundhog; Climate Based Daylight Modelling

\section{Introduction}

For many years, daylight has been a subject of interest in school buildings because it is closely associated with the improvement of students' performance and health conditions [1,2]. Moreover, daylight contributes considerably to the aesthetics and physical character of a learning space, as well as in limiting potential harmful effects from prolonged artificial light exposure [3-5]. In fact, as reported by various researchers, the lack of regular natural light exposure may cause a series of symptoms such as fatigue, stress, circadian dysfunction, phase shifting, and Seasonal Affective Disorder (SAD) amongst building occupants [6-8]. In addition, the exploitation of natural light is an important factor for energy reduction purposes, as pointed out in a report from the International Energy Agency (IEA) where it is shown that artificial lighting is responsible for around $14 \%$ of the electricity consumption in the European Union [9]. Finally, yet importantly, it has been shown that the reduction of energy 
demand for artificial lighting promotes both energy and environmental awareness in the general public [10].

Many research studies have highlighted how ensuring good lighting quality in an educational environment is a rather complex task. A series of different visual activities are performed within the classroom that require specific visual conditions in order to be successfully accomplished. This characteristic is particularly accentuated in historic buildings which are reused for purposes different from their original design, or that cannot be longer used as per their original design [11].

Interestingly, the expression 'historic building' covers a broad range of building typologies. The adjective 'historic', if applied to a building, does not only refer to a building built, and belonging to the past (usually historic buildings are at least 50 years old), but also to a building that holds a relatively high degree of physical integrity [12]. This means that properties such as construction materials, architectural features, constructive elements, and the original architectonic language, must be relatively unchanged with reference to its historic and aesthetic value [13]. In other words, the essential character, relative to its significance, has to be present and, as such, recognizable by people.

According to the Ecosystem School Report of Legambiente released in 2017 [14], about 65\% of Italian school buildings were built before 1974, out of which $22 \%$ were re-adaptation cases. Given the old construction age of most of these premises, in 2014 the Italian Government funded many research projects with the aim of improving the structural safety of historic buildings as well as their indoor comfort conditions. However, little attention has been paid to visual comfort, which has usually been simplistically dealt with, under an energy efficiency perspective for artificial lighting, and thus totally neglecting daylight control.

Out of these historic school buildings, only a small proportion can be considered to belong to cultural heritage, which in Italy fall under the regulations of the Legislative Decree no. 42 of 22 January 2004 (Code of Cultural Heritage and Landscape) [15]. In 2015, some guidelines from the Italian MIBAC (Ministry of Heritage and Cultural Activities and Tourism) were issued that provided indications for the assessment and improvement of the energy performance of the protected cultural heritage. However, these guidelines are only valid as recommendations and have no statutory nature [16].

What thus seems to emerge is a lack of attention regarding the case of historic buildings reused as school buildings, an issue particularly relevant in Italy. Indeed, because of the dissolution of religious corporations and the following confiscation of their real estate from the Italian Government through the so-called subversive laws of 1866/67, a large number of convents were reused for other functions [17]. As an example, the city of Catania in Sicily has 12 convents reused as schools out of a total of 35 [18]. This change in building use highlights the difficulty of matching the conservation needs of historic buildings with the visual comfort needs of the students, a problem also observed in other countries.

In one particular study, Susan and Prihatmanti researched schools in heritage buildings located in Surabaya (Indonesia) from the perspective of the visual discomfort of the occupants, highlighting the use of different indoor finishing layers for the ceiling, the walls, and the floor [19]. Costanzo et al. assessed the effectiveness of several strategies to improve daylight distribution in a side-lit classroom with east-facing windows, e.g., electrochromic glazing, static reflective glazing, blinds, and light shelves in Italy [20]. Michael and Heracleous investigated the daylight performance of typical educational premises in Cyprus, and to this aim made use of several daylight metrics [21]. Pellegrino et al. [22] assessed the daylight performance in classrooms of a school building in Italy, using as reference metrics the Daylight Factor (DF) and some dynamic climate-based metrics. Secchi et al. [23] carried out an integrated thermal-daylight analysis for an existing classroom exposed to the east and located in a town of Tuscany (Italy). All these studies make use of Climate Based Daylight Modelling (CBDM) metrics-most of which have been introduced only recently - because they are based on time series of illuminances (or luminances) rather than on a fixed luminous condition [24]. These time series usually span the whole calendar year and are based on the use of annual solar radiation data for the specific building site. The advantage of dynamic daylight performance metrics, compared to static metrics, is that they consider the quantity and character of daily and seasonal variations of daylight for a given 
building site together with irregular meteorological events [25]. The CBDM metrics employed in this study, which are able to account for variable luminance distributions of the sky throughout a year, are:

- Daylight Autonomy (DA), defined as the percentage of the occupied hours of the year when a minimum illuminance threshold is met by daylight only [26]. According to the original study carried out by IESNA, the 300 lux minimum threshold has been adopted [27].

- Useful Daylight Illuminance (UDI), which represents the percentage of time in which daylight levels fall within certain bins. Usually, three bins are identified by setting a lower and an upper illuminance threshold. The upper bin represents the percentage of time when excessive daylight illuminance occurs, which might lead to visual discomfort; on the other hand, the lower bin represents the percentage of time when daylight illuminance alone is too scarce. Finally, the intermediate bin is the percentage of time when appropriate daylight illuminance is attained. According to the original UDI definition proposed [28], the lower and upper thresholds are set to $100 \mathrm{~lx}$ and $2000 \mathrm{~lx}$ respectively.

This paper focuses on the assessment of the existing lighting conditions of an historical building in the perspective of defining the suitable retrofit solutions for daylighting systems. In detail, we present the approach adopted to assess daylight availability on a representative classroom in a school heritage building located in Syracuse (Italy) using a CBDM approach.

\section{Materials and Methods}

Dynamic metrics, based on local climate data series, have created a new perspective for daylight studies since they capture the particularities of the locale, including daily and seasonal variations of daylight.

As mentioned in the introduction, the metrics used to carry out the assessment of the daylight dynamic performance are the Daylight Autonomy (DA) and the Useful Daylight Illuminance (UDI). In order to calculate these figures, it is necessary to evaluate the time-varying illuminance distribution within the indoor space. In this paper, the calculation was performed for a representative classroom in an historical building. The first step of the study involved a detailed field survey of the geometrical and optical features of the classrooms. To this aim, a Leica 792290 (Leica Camera AG, Wetzlar, Germany) laser distance meter was used for setting up the geometrical model, while a Minolta T-10 lux meter (measurement range of $0.01-300 \mathrm{klx}$, accuracy $\pm 3 \%$ ) and a Minolta LS-100 luminance meter (measurement range of $0.01-50 \mathrm{kcd} / \mathrm{m}^{2}$, accuracy $\pm 0.2 \%$ ) were used for defining the optical properties of different opaque surfaces (Figure 1).

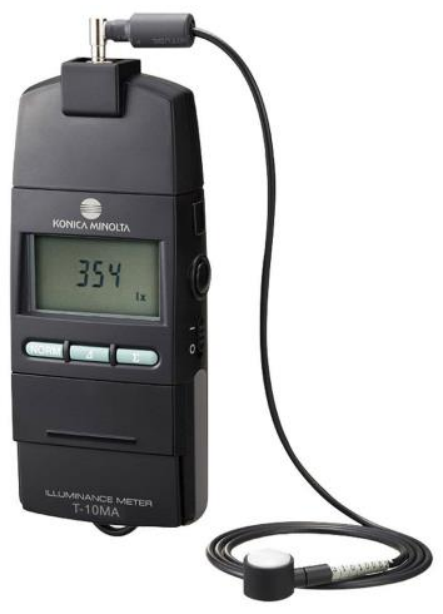

(a)

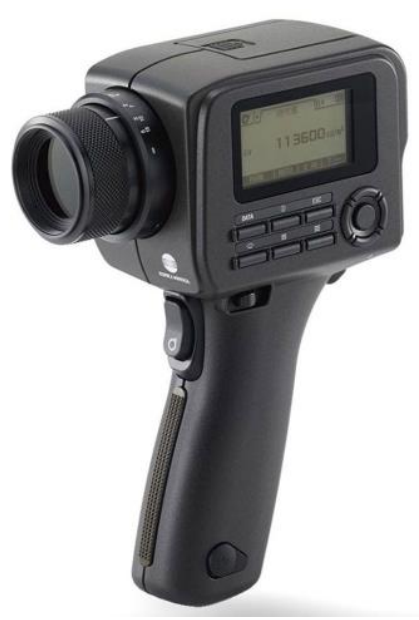

(b)

Figure 1. Minolta T-10 lux meter (a) and Minolta LS-100 luminance (b). 
The values of luminance $(L)$ and illuminance $(E)$ measured on the opaque surfaces allowed to define their visible reflectance $\rho$ under the assumption of Lambertian behavior. Indeed, for diffuse reflection, the following relation holds:

$$
\rho=\frac{\pi L}{E}
$$

Equation (1) was used to evaluate the visible reflectance of opaque surrounding materials of the room. The solar normal transmittance of a representative single sheet of glass (6 mm thickness) of the windows was measured using the spectrophotometer VARIAN Cary 2300 (Agilent 5301 Stevens Creek Blvd, Santa Clara, CA, USA). The spectrophotometer was used to estimate its visual transmittance, varying the wavelength in the range of 350 to $2100 \mathrm{~nm}$ (UV-Vis-NIR fields) according to the European Standard EN 410 [29].

The employed field measurements of natural lighting levels were used for the validation of software simulations, taking into account suggestions previously provided [30] on methods and techniques for effective, accurate, and repeatable in-situ measurements. The validation process was conducted to obtain simulation results matching the levels and distribution of the in-situ measured illuminance levels. Natural lighting measurements were conducted on-site in a classroom during a representative summer period under overcast conditions using the Minolta T-10 lux meter. Illuminance values were taken on 30 different points in a representative classroom at a height of $0.80 \mathrm{~m}$ from the floor according to the national UNI EN 12464-1 Standard [31]. During the monitoring period, the classroom was unoccupied, artificial lighting was not used, and window shades were open.

Simulations were then run using the Groundhog graphical interface for Radiance implemented in Google Sketchup [32-34]. Radiance software was employed to perform daylight simulations using the backward ray-tracing technique in order to examine varying lighting regimes with varying sky models [35]. A validation process was conducted to obtain simulation results as close as possible to the measured values by making all the necessary corrections in terms of geometry and internal surfaces' reflectance, as well as fine-tuning of the Radiance parameters. This process was repeated for many days and in different sky conditions until the achievement of a good match between in-situ and simulated illuminance values. Finally, different measures for the improvement of visual comfort in a representative classroom, taking into account the particularities of an historical building were proposed.

In this regard, several strategies are theoretically possible, most of which are mainly aimed at: (i) Improving the daylight uniformity within the classroom (e.g., by using light shelves on the clerestory of windows); (ii) reducing glare risk close to the windows (e.g., by application of a reflective coating on the outer pane of a window, or by using bi-reflective blinds), and (iii) avoiding too low daylight levels at the back of the classroom (e.g., by means of light tubes or optical fibers) [36]. However, not all of these measures are suitable for historic buildings because of several conservation constraints. Only punctual improvements, carefully designed to be congruent with the architectural particularities of the building, are allowed.

Consequently, this study proposes the use of low-invasive measures, such as windows intrados modification, solar reflective glazing application, and highly-reflective false ceilings. In fact, a different shape of the intrados of the windows allows more daylight from the outer walls to spread to the rest of the room when these are very thick, as is the case in many historical buildings. The higher lighting levels thus achieved are, on the one hand, redirected towards the bottom of the room by means of a highly-reflective diffuse ceiling and, on the other hand, mitigated by using a double-glazed reflective window. Such a window is aesthetically very similar to a single-glazed traditional window and, as such, does not conflict with the historical value of the heritage building. 


\section{Description of the Case Study and of the Experimental Campaign}

\subsection{Gaetano Abela Barrack in Siracusa}

The case study building was the Gaetano Abela Barrack, located in the island of Ortigia (Siracusa, LAT $37^{\circ} 03^{\prime} \mathrm{N}, \mathrm{LON} 17^{\circ} \mathrm{E}$ ). The building was built around 1735 , housing a barrack until the early twentieth century. Since 2005, it has been the seat of the Special Teaching Facility for Architecture of the University of Catania. The urban fabric on which it stands, and the presence of architectural emergencies, such as the Maniace castle (1232-1239), demonstrates the military destination of the district during its history [37].

The building originally had only one floor, and was elevated in the 1930s. From a distribution point of view, it is a rectangular building with a large internal courtyard used for military exercises (Figure 2). Several rooms surround the courtyard, with different dimensions depending on the destination.

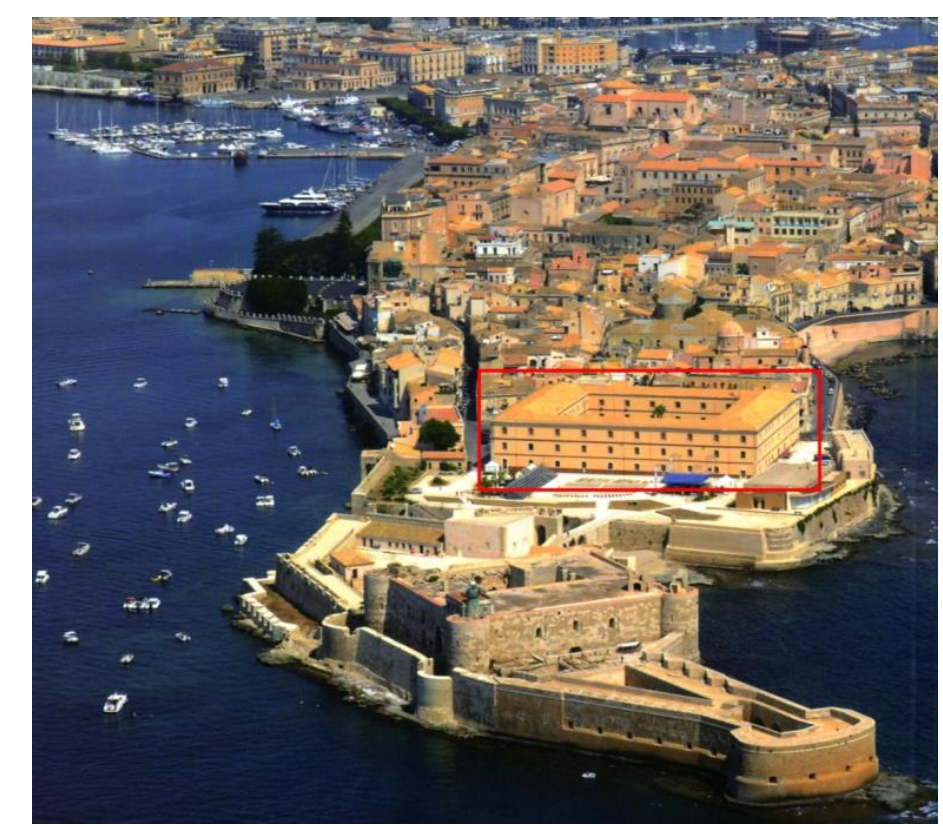

(a)

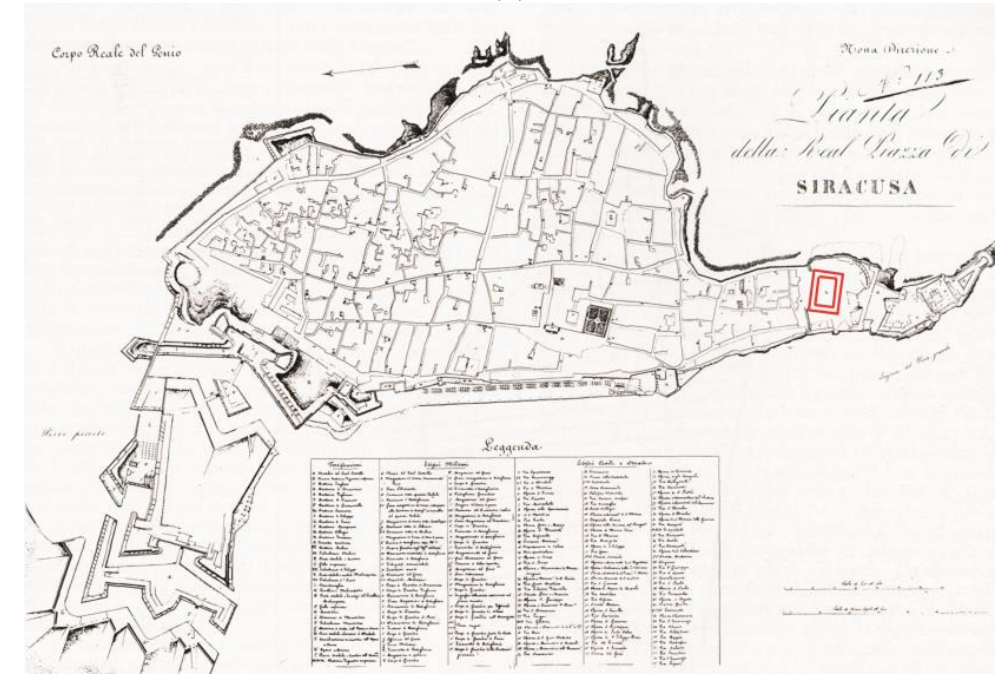

(b)

Figure 2. A bird's eye view of Ortigia Island (a). A planimetric view of the city of Siracusa, 1840 (b). The Gaetano Abela Barrack is highlighted in red in both panels. 
The building's original designation as a military barrack led to the use of a compact building shape, not permeable with the outside. The windows on the external facades, in fact, are small $\left(1.7 \mathrm{~m}^{2}\right)$ and protected by grilles. The inner windows, facing the courtyard, are larger (almost $2.2 \mathrm{~m}^{2}$ ) and light the rooms.

The barrack was built with a technological system that varies according to the construction period. The structural system is in bearing masonry made in blocks of tender limestone (thicknesses from 0.86 to $0.65 \mathrm{~m}$ from ground to upper floors in order in Figure 3). The horizontal closures (the oldest ones) are vaulted on the ground floor while reinforced concrete floors, built in the Hennebique system, can be found on the upper ones. Pitched roofs covered with a mantle of Spanish tiles rest on wooden trusses that hold a continuous plank.

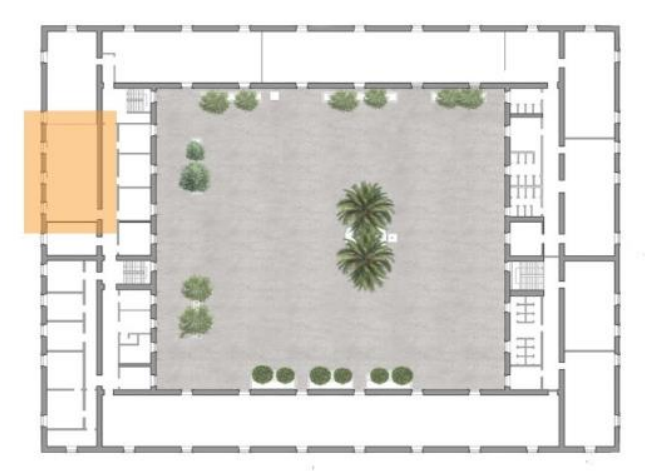

(a)
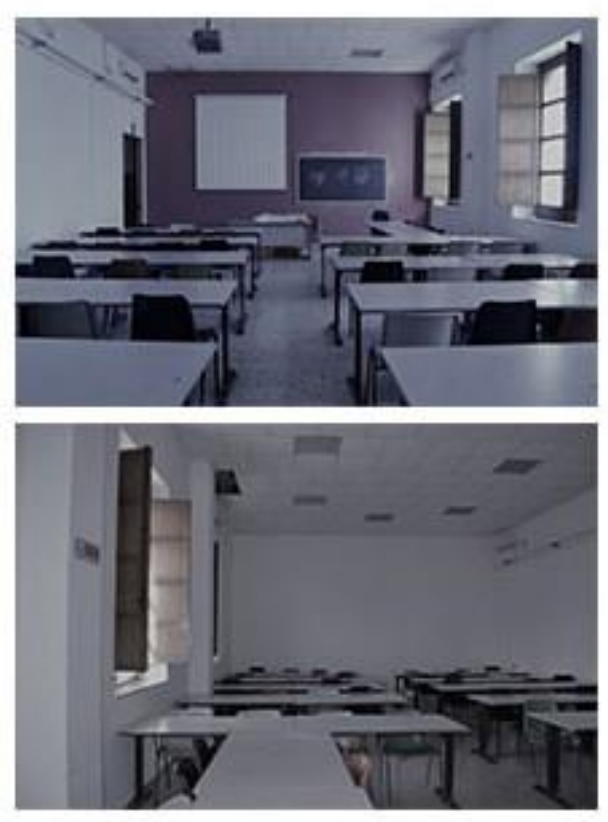

(b)

Figure 3. A plan view of the building with the classroom analyzed highlighted in orange (a) and its internal views (b).

The classroom, which was the object of study, faces west, is rectangular in shape $\left(6.52 \times 12.19 \mathrm{~m}^{2}\right.$ wide, with a resulting net floor area of about $\left.79.48 \mathrm{~m}^{2}\right)$, and is equipped with three windows of $1.3 \times 1.7 \mathrm{~m}^{2}$ dimension each, located at around one meter from the floor, and provided with a wooden frame. The entrance door has two shutters-one fixed and one mobile-with an aluminum frame and does not contribute to the illuminance of the space. The false ceiling height is approximately $3.50 \mathrm{~m}$ and is made of white gypsum panels. Apart from the traditional school furniture composed of desks, chairs, and the blackboard, the classroom is equipped with a video projector with a wall screen used for lecture activities and for presentations from the students.

After the definition of the geometrical characteristics of the classroom, a series of measurements were taken with the aim of characterizing the optical properties of the surfaces enveloping the space (in terms of visible reflectance of the opaque surfaces and visible transmissivity of transparent surfaces respectively, see Table 1), and the illuminance levels on the work plane.

The work plane was defined as an ideal horizontal surface located at $0.80 \mathrm{~m}$ from the floor (corresponding to the height of the desks) where the main visual task takes place (UNI EN 12464-1: 2011 standard [31]). Table 1 sums up the optical properties of the materials making up the room; these values are then used as input for the simulations in Radiance. 
Table 1. Optical properties of the materials in the classroom.

\begin{tabular}{cc}
\hline Surface & Reflectance/Transmissivity * \\
\hline Floor & 0.4 \\
White plaster & 0.8 \\
Red plaster & 0.3 \\
Computer terminal & 0.8 \\
Board & 0.07 \\
Desks & 0.5 \\
Red door & 0.4 \\
Window wood & 0.2 \\
Light glass window fixtures * & 0.75 \\
\hline
\end{tabular}

* Transmissivity is only for window glass.

\subsection{Model Validation}

The illuminance values inside the classroom were measured on a horizontal grid of 30 equally distributed points spaced $1.10 \times 2.20 \mathrm{~m}^{2}$ and placed at $0.80 \mathrm{~m}$ from the floor at 12:30 a.m. on 14 May under slightly overcast conditions (see in Figure 4). The points adjacent to the perimeter walls were spaced $1.54 \mathrm{~m}$ from the south wall, $0.66 \mathrm{~m}$ from the west wall, $0.55 \mathrm{~m}$ from the north wall, and $0.66 \mathrm{~m}$ from the east wall in order.

Groundhog is a type of software that needs local climate data, both to calculate the position of the sun in the sky and to convert the values of the global horizontal radiation in a luminance distribution for the sky, according to Perez's model.

These luminance values were then transformed into illuminance values for each point belonging to the sensor's grid defined by the user following the daylight coefficients approach [5]. The climate data needed for the simulations was retrieved from the EnergyPlus software portal in .epw format (Typical Meteorological Year with hourly distribution of meteorological data) from the nearest weather station of Catania-Fontanarossa. This was done because no climate data was available for the city of Siracusa; however, no significant differences were expected because both cities are on the sea level and are situated just $40 \mathrm{~km}$ away from each other.

For the sake of validating the model and adjusting the basic parameters used by Radiance in the simulations (reported in Table 2), several iterations were performed until an average error of less than $7 \%$ was achieved between the measured and simulated illumination profiles for each point of the analysis grid. It is important to notice that the simulated results refer to 9 May (and not 14 May) because this was the day from the EnergyPlus weather file that shows sky conditions very close to those of the measurement day while keeping the same solar height. Although not perfectly accurate, this procedure was followed to overcome the limitations deriving from the lack of real-time monitored weather data, and the consequent use of Typical Meteorological weather data was used for validation purposes.

Table 2. Radiance parameters used in the simulations.

\begin{tabular}{ccccc}
\hline$-a b$ & $-a a$ & $-a d$ & $-a s$ & $-a r$ \\
\hline 4 & 0.075 & 2048 & 512 & 512 \\
\hline
\end{tabular}

Ambient bounces $-a b$ (i.e., the maximum number of bounces of the diffuse indirect component of daylight) was set to 4 to accurately account for diffuse reflection within the room, and accordingly the ambient resolution parameter -ar was set to 512 to have a high density of ambient values used for interpolation. On the other hand, the ambient super-samples - as and ambient divisions - ad parameters were set to quite a low resolution (512 and 2048 respectively) to keep simulation times reasonable. However, these parameters were mainly used for rendering visualization and did not affect the calculation outcomes. 
From the comparison shown in Figure 4 and in Table 3 it is possible to see how the gap between measured and simulated illuminance is little, and acceptable for each sensor; in this way the calculation model was considered validated to perform the annual simulations discussed in the following section.

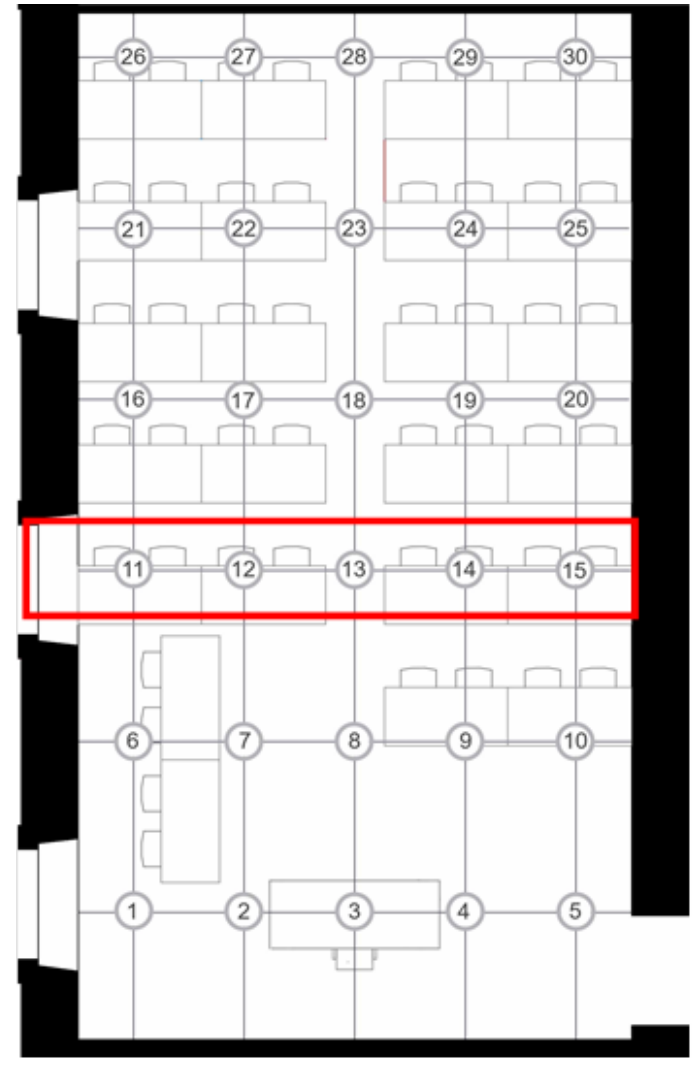

(a)

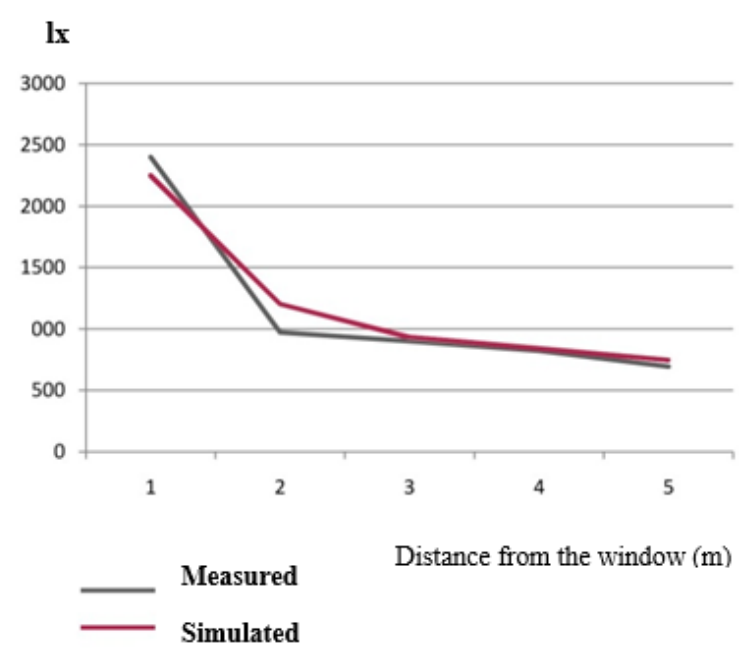

(b)

Figure 4. Analysis grid points (a) and a transversal profile of the measured and simulated illuminance levels along the row of points 11-15 (highlighted in red) at 12:30 a.m. on 14 May under slightly overcast sky conditions (b).

Table 3. Comparison between measured and simulated illuminance for the measurement day (12:30 a.m. on 14 May under slightly overcast sky conditions).

\begin{tabular}{ccc}
\hline Point & Measured Values & Simulated Values \\
\hline 1 & 2400 & 2250 \\
2 & 972 & 1203 \\
3 & 900 & 932 \\
4 & 822 & 845 \\
5 & 694 & 750 \\
6 & 703 & 775 \\
7 & 812 & 1090 \\
8 & 744 & 750 \\
9 & 699 & 732 \\
10 & 670 & 717 \\
11 & 2120 & 2180 \\
12 & 1057 & 1273 \\
\hline
\end{tabular}


Table 3. Cont.

\begin{tabular}{ccc}
\hline Point & Measured Values & Simulated Values \\
\hline 13 & 678 & 765 \\
14 & 640 & 724 \\
15 & 631 & 704 \\
16 & 692 & 767 \\
17 & 791 & 1103 \\
18 & 763 & 784 \\
19 & 677 & 697 \\
20 & 652 & 681 \\
21 & 2360 & 2122 \\
22 & 968 & 1001 \\
23 & 883 & 922 \\
24 & 803 & 888 \\
25 & 625 & 680 \\
26 & 637 & 663 \\
27 & 759 & 812 \\
28 & 757 & 791 \\
29 & 631 & 689 \\
30 & 620 & 647 \\
\hline
\end{tabular}

\section{Results and Discussion}

\subsection{Existing Scenario}

From the analysis of the illuminance values carried out at 12:30 a.m. on 14 May, it is evident how higher levels (around 2250 lx, see Figure 5) were recorded in correspondence of the areas below the glazed surfaces. For all the other points, the illuminance kept consistently higher than the minimum threshold of $300 \mathrm{~lx}$ set by the existing legislation in Italy [31]. The average illuminance was about $850 \mathrm{~lx}$ on around $60 \%$ of the work plane, while the uniformity ratio (i.e., the ratio between the minimum and the average illuminance) was 0.67. It therefore showed a good distribution of light in conditions of overcast sky without excessive asymmetries between the areas close to the glazed surfaces and the remaining.

If extending the analysis period to an entire year, the UDI (hereafter the 'useful' range will be considered, that is to say the bin of $500<$ UDI < 2000) and DA parameters reported in Figure 6 show how the space would keep a good illuminance distribution for most of the useful surface for about $70 \%$ of the time. In fact, the areas close to the windows show values higher than $2000 \mathrm{~lx}$ for about $40 \%$ of the time. However, this may lead to potential glare issues for the users. The back and the remaining areas of the classroom are instead characterized by an insufficient illuminance for at least $5 \%$ of the time. DA calculations, on the other hand, show how, for about $90 \%$ of the time, the illuminance is over the minimum threshold set at $300 \mathrm{~lx}$ almost everywhere.

What is therefore evident from yearly simulations of the existing scenario is that:

- In the classroom there was a good availability of natural light, expressed by an average DA value of $90 \%$;

- Glare issues may occur near the glazed surfaces also under overcast sky conditions. This is pointed out by the UDI calculation, which highlights illuminance values higher than $2000 \mathrm{~lx}$ for about $40 \%$ of the time on average for the study points. 


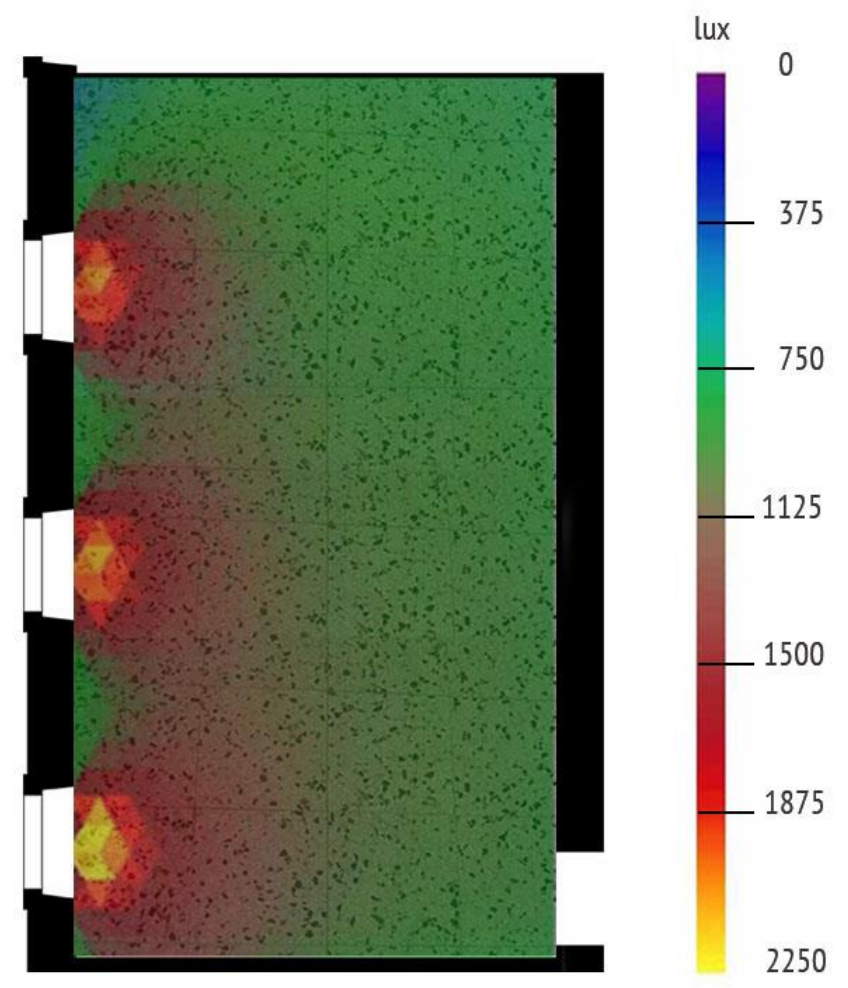

Figure 5. Illuminance distribution on 14 May under overcast sky conditions. Existing scenario.

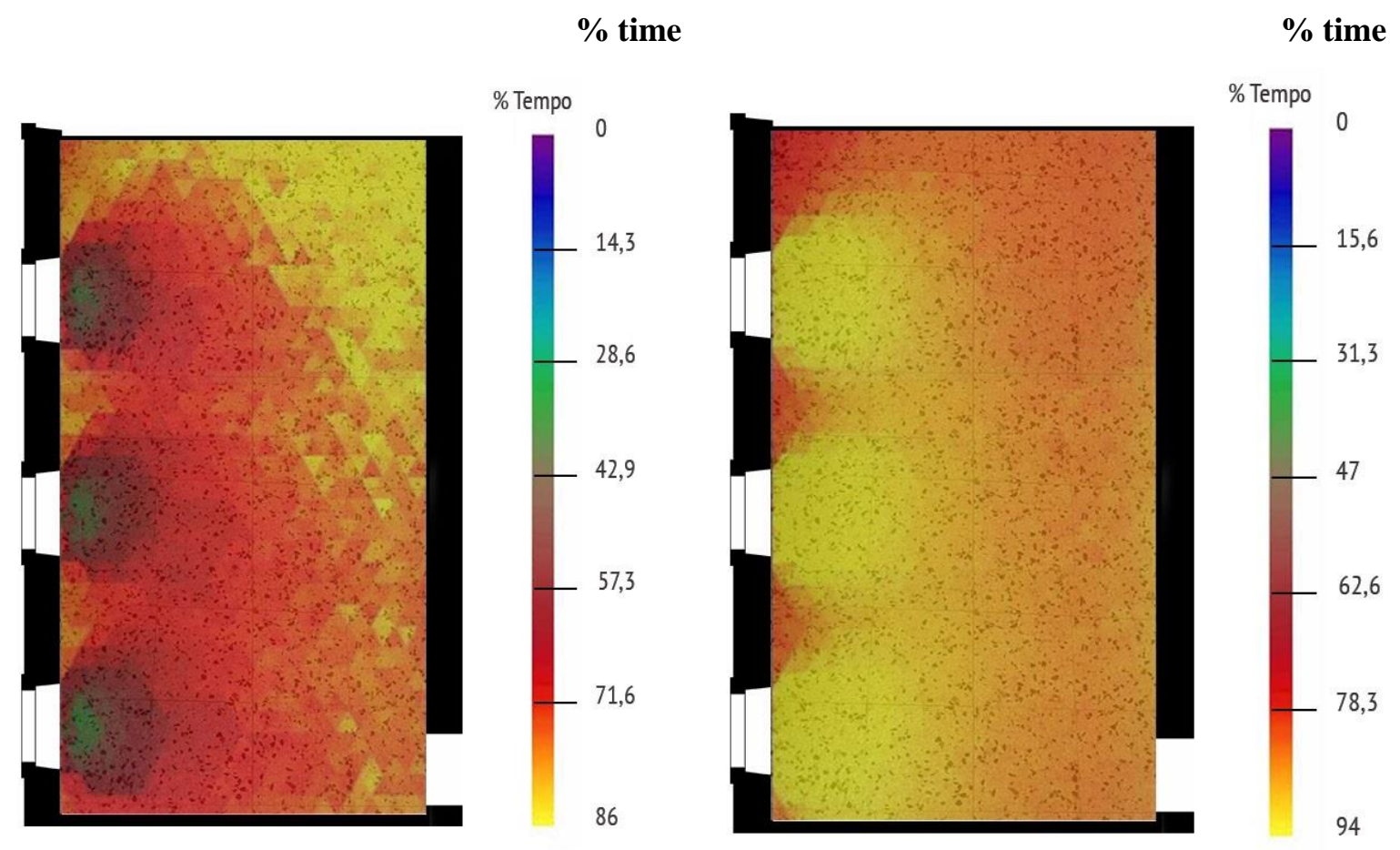

(a)

(b)

Figure 6. Useful Daylight Illuminance (UDI) distribution (a) and Daylight Autonomy (DA) distribution (b). Existing scenario. 


\subsection{Retrofit Scenario}

As previously stated in Section 2, the historic value of the building poses several constraints in terms of viable retrofit solutions. It has been therefore decided to take action with improvement proposals that are punctual, non-invasive, and carefully studied to suit the architectural features of the building. In detail, it has been decided to replace the existing clear glass of transmissivity $\tau=0.75$ with a double-glazed unit of lower resulting transmissivity $(\tau=0.60)$. In this way, the incoming light from the windows is reduced, thus lessening the risk of glare for those occupants sit in close proximity of the windows.

Furthermore, the traditional wooden-framed windows allow for an easy replacement of the existing glass sheets with new ones of greater thickness, by introducing new little wooden frames [38].

In order to avoid the excessive reduction of daylight levels in the areas furthest away from the windows, it is proposed to give a divergent section to the intrados of the windows by cutting the wall obliquely $0.2 \mathrm{~m}$ on the right, left, and upper sides. This will have positive effects for natural light to enter and spread in the environment, because of the high thickness of perimeter walls (about $0.8 \mathrm{~m}$ ). In addition, it has also been hypothesized that the introduction of a double-curved false ceiling with highly-reflective panels $(\rho=0.8)$ in natural fiber would facilitate a uniform redistribution of daylight in the most remote areas of the classroom. To improve its performance, apart from the curvature, several iterations have been made for the estimation of the optimal tilt angle. The panels have a thickness of $6 \mathrm{~mm}$ and can be hooked to a metal support structure made of an aluminum profile, which will be hung in turn on the existing concrete ceiling. Consequently, the false ceiling has a height difference between the external and internal walls, as reported in Figure 7 where the different solutions proposed are of around $0.6 \mathrm{~m}$.
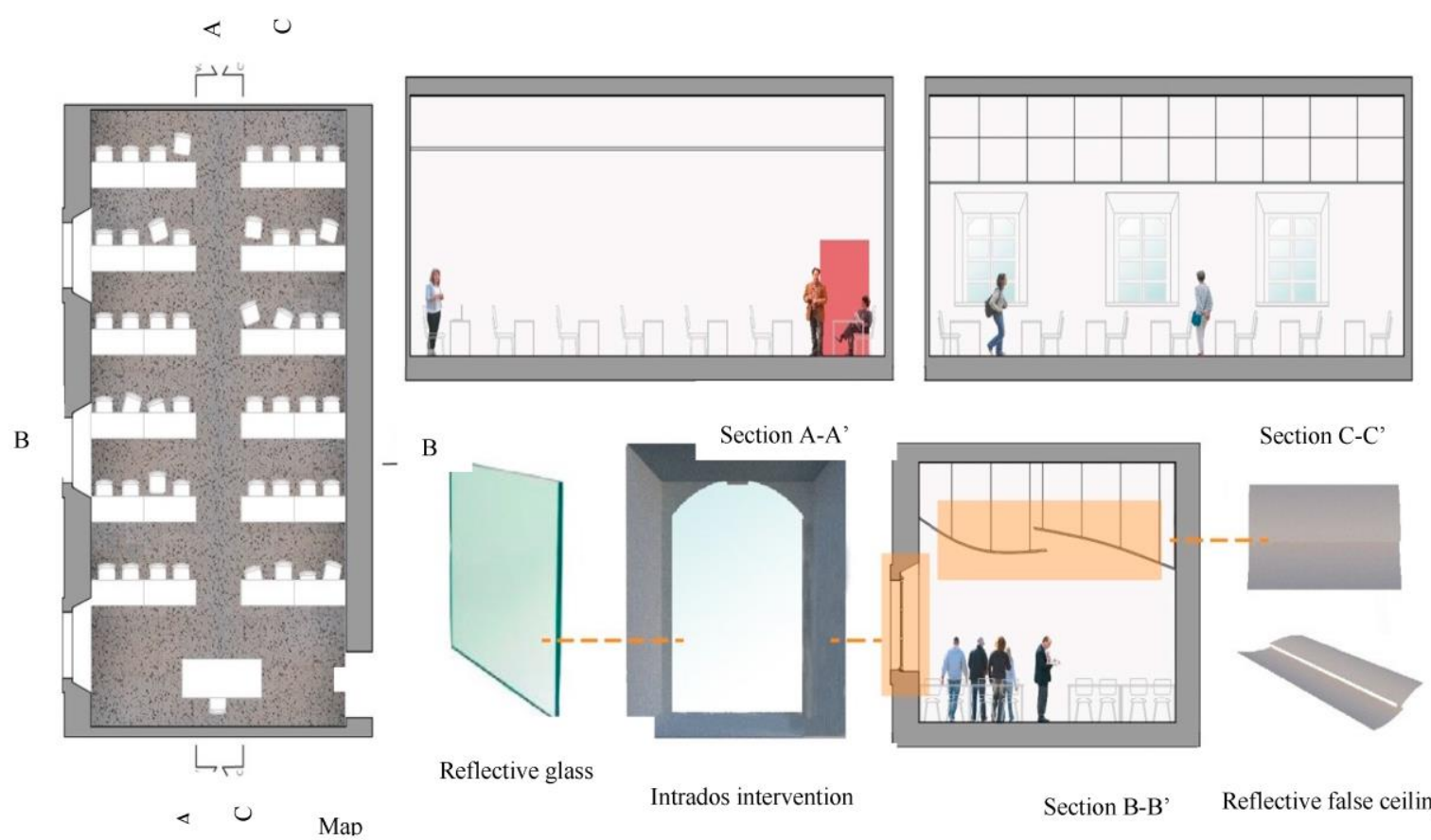

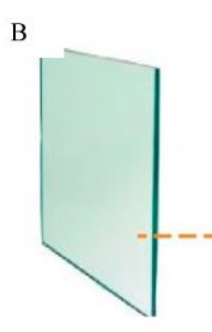

Reflective glass

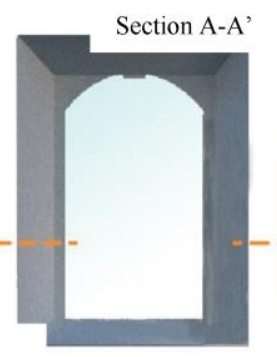

Intrados intervention

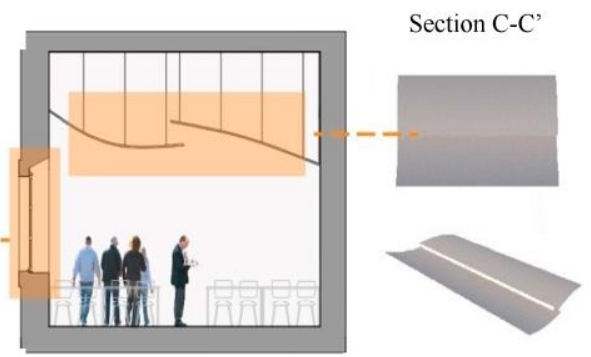

Section B-B'

Reflective false ceiling

Figure 7. Retrofit solutions: Countersink of the intrados of the windows, reflective glazing, and highly-reflective false ceiling.

By running the daylight simulations, with the implementation of the above-mentioned retrofit solutions, the classroom showed an average illuminance value under overcast sky conditions of about $350 \mathrm{~lx}$ (the time considered is the same discussed for the existing scenario to allow a direct comparison, see Figure 8). 

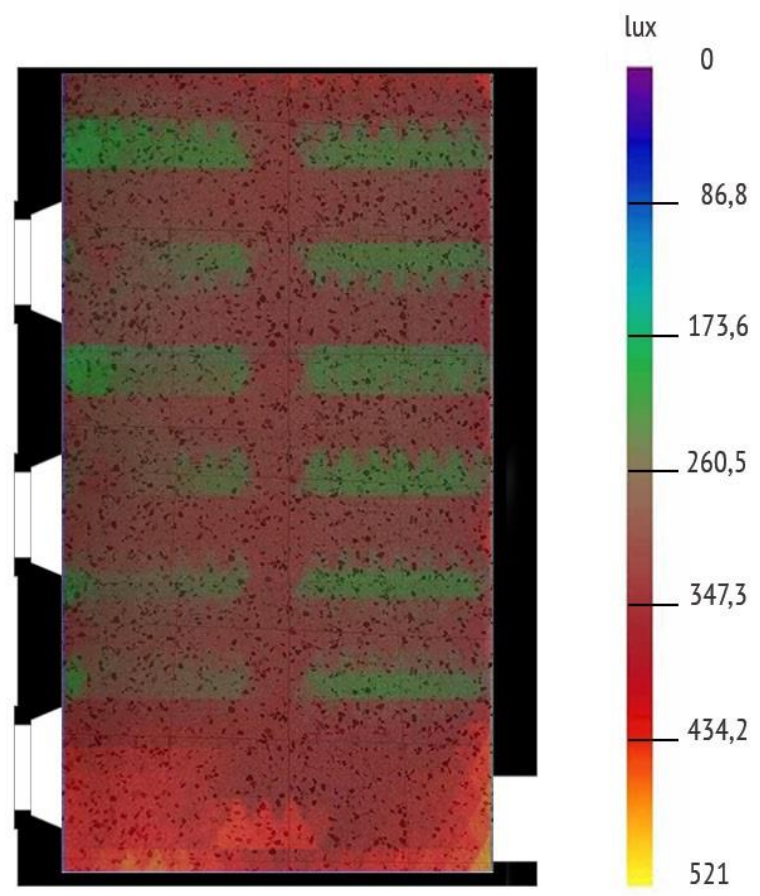

Figure 8. Illuminance distribution on 14 May under overcast sky conditions. Retrofit scenario.

The desks registered illuminance values ranging between 170 and $3201 x$, while the area facing the blackboard reached an illuminance value of around 500 lx. The UDI distribution reported in Figure 9 shows how most of the useful surface had very good levels of illuminance for more than $70 \%$ of the time in a year. In particular, only in rare cases (less than $15 \%$ of the time) illuminance values higher than 2000 lx were registered near the windows. The DA distribution confirms this result, showing how on average, for $95 \%$ of the simulated time, illuminance was higher than the minimum threshold of 300 lx, but with a more uniform distribution in comparison to the base case depicted in Figure 6.

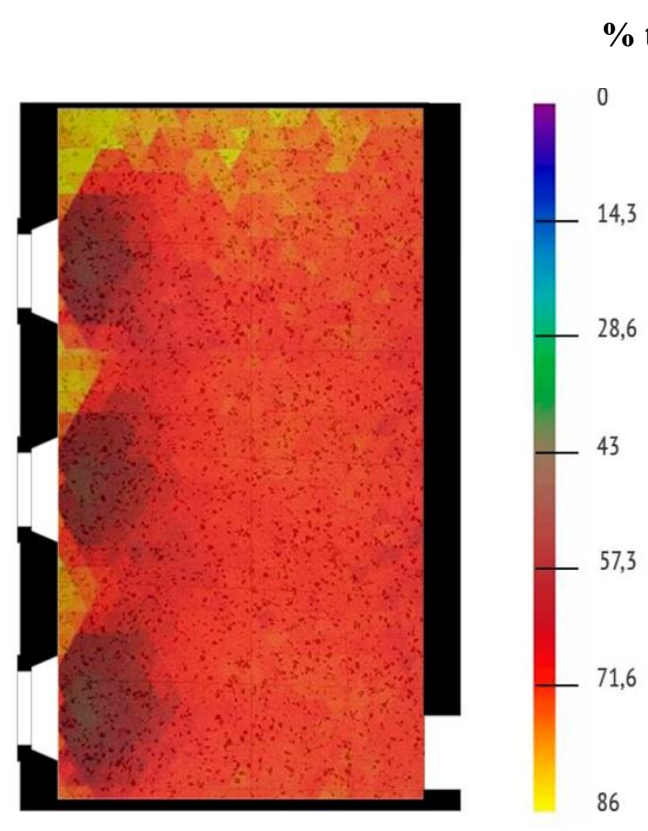

(a)
\% time

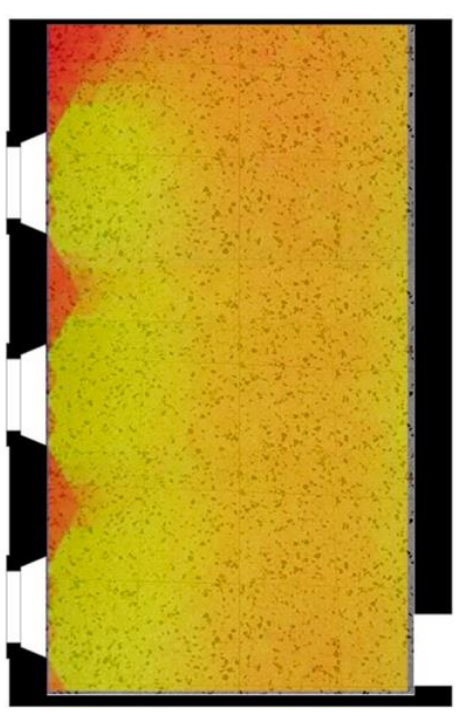

$\%$ time

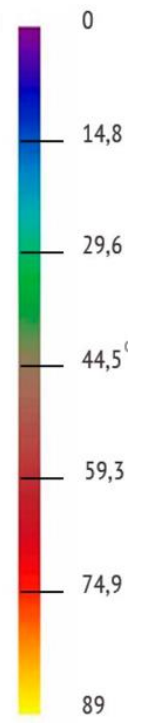

(b)

Figure 9. UDI distribution (a) and DA distribution (b). Retrofit scenario. 


\section{Conclusions}

This article explored the optimization of natural light within an historic building reused as a university teaching building located in Siracusa (Italy).

If daylighting issues are easy to manage in new buildings through an accurate design phase, then when considering a retrofit intervention on existing buildings-especially on heritage buildings - more accurate and careful evaluations are required.

With the help of an accurate survey of the geometric, technological, and illuminance characteristics of the case study building, a validated daylight model in Radiance was built using the Groundhog plug-in for Google Sketchup. The use of Climate Based Daylight Metrics such as the Useful Daylight Illuminance (UDI) and the Daylight Availability (DA) have made it possible to identify, on an annual basis and under variable sky conditions, the main problems of a sample classroom. The main issues found regard excessive illuminance levels near the windows and too low illuminance values when away from them. In order to reduce the potential glare risks for students sitting near the windows, without negatively affecting the illuminance levels in the remaining areas, the installation of double-glazed windows together with a highly-reflective and diffuse false ceiling was suggested. The study of the new geometric layout given by the flaring of the window frames and the double curvature of the inclined false ceiling allows for a more even distribution of daylight inside the classroom.

All the proposed interventions are compatible with the historic-aesthetic value of the case study building and represent viable solutions to the improvement of natural light conditions inside school buildings. This exercise demonstrates how a careful daylight analysis carried out using state-of-the-art CBDM metrics can inform the design of refurbishment interventions also in heritage buildings, which are typically characterized by several architectural constraints.

Author Contributions: F.N. and V.C. designed the research; F.N. and A.L.F. wrote the Introduction and Materials and Methods; A.L.F. and C.R. described the case study; F.N. and C.R. wrote the Model calibration, the Units of measurements used and the Results; F.N., A.L.F. and V.C. reviewed the paper and contributed equally to the Discussion and Conclusion sections.

Funding: This research received no external funding.

Conflicts of Interest: The authors declare no conflict of interest.

\section{References}

1. Dunn, R.; Krimsky, J.S.; Murray, J.B.; Quinn, P.J. Light up their lives: A research on the effects of lighting on children's achievement and behaviour. Read. Teach. 1985, 38, 863-869.

2. Kuller, R.; Lindsten, C. Health and behaviour of children in classroom with and without windows. J. Environ. Psychol. 1992, 12, 305-317. [CrossRef]

3. Heschong, L.; Write, L.R.; Okura, S. Daylighting impacts on human performance in school. J. Hum. Eng. Soc. 2002, 31, 101-117. [CrossRef]

4. Baker, N.; Steemers, K. Daylight Design of Buildings; Routledge: London, UK, 2002; ISBN 1873936885.

5. Mirrahimi, S.; Lukman, N.; Ibrahim, N.; Surat, M. Effect of daylighting on student health and performance. In Proceedings of the 15th International Conference on Mathematical and Computational Methods in Science and Engineering, Kuala Lumpur, Malaysia, 2-4 April 2013; WESEAS Press: Grete, Greece, 2013; pp. 127-132.

6. Küller, R.; Ballal, S.; Laike, T.; Mikellides, B.; Tonello, G. The impact of light and colour on psychological mood. Ergonomics 2006, 49, 1496-1507. [CrossRef] [PubMed]

7. Boyce, P.; Hunter, C.; Howlett, O. The Benefits of Daylight through Windows; Lighting Research Center, Rensselaer Polytechnic Institute, Troy: New York, NY, USA, 2003.

8. British Standards Institution. BS 8206-2: 2008. Lighting for Buildings-Part 2: Code of Practice for Daylighting; British Standards Institution: London, UK, 2008.

9. International Energy Agency. Available online: http://www.iea.org/ (accessed on 8 October 2018).

10. US Green Building Council. LEED-NC (Leadership in Energy and Environmental Design). Version 2.2. 2006. Available online: www.usgbc.org/LEED/ (accessed on 6 September 2018). 
11. Prihatmanti, R.; Bahauddin, A. The indoor environmental quality of UNESCO listed heritage buildings, George Town, Penang. In Proceedings of the 5th International Conference on Built Environment in Developing Countries, Penang, Malaysia, 6 December 2011.

12. Mazzarella, L. Energy retrofit of historic and existing buildings. The legislative and regulatory point of view. Energy Build. 2015, 95, 23-31. [CrossRef]

13. Brandi, C. Teoria del Restauro; Einaudi: Torino, Italy, 1977; ISBN 8806155652.

14. Ecosistema Scuola. XVIII Rapporto di Legambiente Sulla Qualità Dell'Edilizia Scolastica, Delle Strutture e Dei Servizi; Ecosistema Scuola: Rome, Italy, 2017; Available online: https:/ /www.legambiente.it/contenuti/ dossier / ecosistema-scuola-2017 (accessed on 25 September 2018).

15. Presidenza Repubblica Italiana, Decreto Legislativo 22 Gennaio 2004, n. 42, Codice Dei Beni Culturali e Del Paesaggio, ai Sensi Dell'Articolo 10 Legge 6 Luglio 2002, n. 137. GU n.45 Del 24-2-2004-Suppl. Ordinario n. 28. Available online: http://www.bncrm.beniculturali.it/getFile.php?id=466 (accessed on 6 September 2018).

16. Linee di Indirizzo Per il Miglioramento Dell'Efficienza Energetica nel Patrimonio Culturale. Architettura, Centri e Nuclei Storici ed Urbani, Rome, 2015. Available online: http://www.pabaac.beniculturali.it/ opencms /opencms/BASAE/sito-BASAE/contenuti/aree/Notizie/Direzione-generale/visualizza_asset. html?id=9195\&pagename $=19$ (accessed on 6 September 2018).

17. Bresci, D. Le leggi di liquidazione dell'asse ecclesiastico nel biennio 1866-1867: Un iter complesso e una soluzione traumatica. In La Soppressione Delle Corporazioni Religiose e la Liquidazione Dell'Asse Ecclesiastico nell'Italia Unita: Il caSo Toscano e le Fonti Archivistiche (1866-1867); Ciuffoletti, Z., Corradi, G.L., Eds.; Mandragora: Firenze, Italy, 2014; pp. 23-43. ISBN 9788874612185.

18. Spina, R. Cessione di Fabbricati Monastici Per la Pubblica Utilità a Catania; Aracne Editrice Srl: Roma, Italy, 2012; ISBN 8854850624.

19. Yohana, S.M.; Prihatmanti, R. Daylight characterization of classrooms in heritage school buildings. Plan. Malaysia 2017, 15, 209-220. [CrossRef]

20. Costanzo, V.; Evola, G.; Marletta, L.; Panarelli, D. Static and dynamic strategies for improving daylight use in side-lit classrooms: A case study. In Proceedings of the BSA 2017-3rd IBPSA Italy, Bolzano, Italy, 8-10 February 2017; Bu Press: Bolzano, Italy, 2018.

21. Michael, A.; Heracleous, C. Assessment of natural lighting performance and visual comfort of educational architecture in Southern Europe: The case of typical educational school premises in Cyprus. Energy Build. 2017, 140, 443-457. [CrossRef]

22. Pellegrino, A.; Commarauno, S.; Savio, V. Daylighting for green schools: A resource for indoor quality and energy efficiency in educational environments. Energy Procedia 2015, 78, 3162-3167. [CrossRef]

23. Secchi, S.; Sciurpi, F.; Pierangioli, L.; Randazzo, M. Retrofit strategies for the improvement of visual comfort and energy performance of classrooms with large windows exposed to East. Energy Procedia 2015, 78, 3144-3149. [CrossRef]

24. Reinhart, C.F.; Mardaljevic, J.; Rogers, Z. Dynamic Daylight Performance Metrics for Sustainable Building Design. Leukos 2006, 3, 7-31. [CrossRef]

25. Mardaljevic, J. Simulation of annual daylighting profiles for internal illuminance. Light. Res. Technol. 2000, 32, 111-118. [CrossRef]

26. Reinhart, C.F.; Walkenhorst, O. Radiance-based daylight simulations for a full-scale test office with outer venetian blinds. Energy Build. 2001, 33, 683-697. [CrossRef]

27. Standard IES LM-83-1. Approved Method: IES Spatial Daylight Autonomy (sDA) and Annual Sunlight Exposure (ASE); Illuminating Engeneering Society: New York, NY, USA, 2012.

28. Nabil, A.; Mardaljevic, J. Useful daylight illuminances: A replacement for daylight factors. Energy Build. 2006, 38, 905-913. [CrossRef]

29. European Committee for Standardization. CEN EN 410. Glass in Building-Determination of Luminous and Solar Characteristics of Glazing; European Committee for Standardization: Bruxelles, Belgium, 1998.

30. Richman, E.E. Standard Measurement and Verification Plan for Lighting Retrofit Projects for Buildings and Building Sites; Report PNNL-21983; U.S. Department of Energy, Pacific Northwest National Laboratory: Washington, DC, USA, 2012.

31. Thorn Lighting. EN12464-1:2011. Light and Lighting_Lighting of Workplaces. Part 1: Indoor Work Places; Thorn Lighting: Spennymoor, UK, 2011. 
32. Think in 3D. Draw in 3D. Available online: https://www.sketchup.com (accessed on 6 September 2018).

33. RADSITE. Available online: https://www.radiance-online.org/download-install/radiance-source-code/ latest-release (accessed on 6 September 2018).

34. Documentation Your Users Will Love! Available online: https://groundhoglighting.gitbooks.io (accessed on 6 September 2018).

35. Lim, Y.W.; Ahmad, M.H.; Ossen, D.R. Empirical validation of daylight simulation tool with physical model measurement. Am. J. Appl. Sci. 2010, 7, 1426-1431.

36. Reinhart, C.F.; Weissman, D.A. The daylit area-correlating architectural student assessments with current and emerging daylight availability metrics. Build. Environ. 2011, 50, 155-164. [CrossRef]

37. Adorno, S. Siracusa 1880-2000: Città, Storia, Piani; Marsilio Editore: Venezia, Italy, 2006; ISBN 883178760.

38. Moschella, A.; Gagliano, A.; Lo Faro, A.; Mondello, A.; Salemi, A.; Sanfilippo, G. A Methodology for an Integrated Approach for Seismic and Energy Refurbishment of Historic Buildings in Mediterranean Area. Sustainability 2018, 10, 2448. [CrossRef]

(C) 2018 by the authors. Licensee MDPI, Basel, Switzerland. This article is an open access article distributed under the terms and conditions of the Creative Commons Attribution (CC BY) license (http:/ / creativecommons.org/licenses/by/4.0/). 